\title{
Lipopolysaccharide worsens the prognosis of experimental cerebral ischemia via interferon gamma-induced protein 10 recruit in the acute stage
}

Ping Wang ${ }^{1}$, Jiaqi Zhang ${ }^{3}$, Feifei Guo ${ }^{1}$, Shuang Wang ${ }^{3}$, Yi Zhang ${ }^{1}$, Defeng $\mathrm{Li}^{1}$, Haiyu X $\mathrm{u}^{1,2^{*}}$ (D) and Hongjun Yang ${ }^{\text {* }^{*}}$

\begin{abstract}
Background: Infection is an important clinical complication facing stroke-patients and triples the risk of death within 30 days post-stroke via mechanisms which are poorly understood.

Aims: We tried to explore the mechanisms that inflammation caused by infections aggravated the ischemic brain injury after middle cerebral artery occlusion (MCAO).

Methods: We used lipopolysaccharide (LPS) as systemic inflammatory stimuli to explore the mechanisms of aggravated ischemic brain injury after Sprague-Dawley male rats subjected to MCAO. Brain damage was evaluated by cerebral blood perfusion, Longa-5 scores, infarct volume and edema degree. Systemic cytokine responses and inflammatory changes in the plasma and brain were analyzed by ELISA kit, $R T^{2}$ Profiler ${ }^{\mathrm{TM}}$ PCR array, and quantitative real-time $P C R$. The differential genes were subjected to Gene Ontology enrichment analysis and protein-protein interaction (PPI) network construction.

Results: Lipopolysaccharide profoundly aggravated the brain damage after $24 \mathrm{~h}$ post-MCAO. At the acute stage (ischemia/reperfusion $90 \mathrm{~min} / 3 \mathrm{~h}$ ), the brain homogenate gene expression of interleukin 6 (IL-6), tumor necrosis factor a (TNF-a), interleukin $1 \beta$ (IL-1 $\beta$ ) and Interferon gamma-induced protein 10 (IP-10) was significantly up-regulated and the contents in plasma and brain homogenate were significantly increased in MCAO and MCAO + LPS group. IP-10 was the only gene with significant difference between MCAO and MCAO + LPS group, which was also in an important position with degrees of $\geq 14$ in PPI network.
\end{abstract}

Conclusions: It was possible that trace LPS aggravated the ischemic brain injury by induction of excessive IP-10 secretion in the acute stage, leading to excessive inflammatory response, which consequently increased the infarct volume and edema degree $24 \mathrm{~h}$ post-MCAO.

Keywords: MCAO, LPS, Inflammation, Cerebral ischemia

*Correspondence: hy_xu627@163.com; hongjun0420@vip.sina.com 1 Institute of Chinese Materia Medica, China Academy of Chinese Medical Sciences, Beijing 100700, China

Full list of author information is available at the end of the article

\section{Background}

The incidence of first-ever stroke increased rapidly worldwide, and presented younger trend [1,2]. Stroke is a devastating cerebrovascular event that the blood suddenly stops flowing smoothly to the brain, due to the blockage (ischemic stroke) or rupture (hemorrhagic stroke), which is a leading cause to morbidity and mortality. Numerous

(c) The Author(s) 2019. This article is licensed under a Creative Commons Attribution 4.0 International License, which permits use, sharing, adaptation, distribution and reproduction in any medium or format, as long as you give appropriate credit to the original author(s) and the source, provide a link to the Creative Commons licence, and indicate if changes were made. The images or other third party material in this article are included in the article's Creative Commons licence, unless indicated otherwise in a credit line to the material. If material is not included in the article's Creative Commons licence and your intended use is not permitted by statutory regulation or exceeds the permitted use, you will need to obtain permission directly from the copyright holder. To view a copy of this licence, visit http://creativeco mmons.org/licenses/by/4.0/. The Creative Commons Public Domain Dedication waiver (http://creativecommons.org/publicdomain/ zero/1.0/) applies to the data made available in this article, unless otherwise stated in a credit line to the data. 
neuronal necrosis and immunocyte extreme infiltration is one of the hallmarks of ischemic stroke. Chemokines play an important role in inflammatory response [3]. Microglia, the resident macrophage population of the central nervous system (CNS) could be activated by any type of brain pathology and migrate to the injury site as up-regulating the expression of chemokine receptor, which aggravates the inflammation in the injured area. Otherwise, chemokine controls the peripheral white blood cells to enter the ventricle through the blood-brain barrier with increased permeability, release a variety of pro-inflammatory cytokines and promote inflammatory response. Moderate activation of microglia and appropriate infiltration of leukocyte are beneficial to the removal of cell debris from infarcted areas. However, if the activation and recruitment last too long, excessive inflammatory response would aggravate brain injury. It is undoubtedly that the inflammation cascade induced by stroke aggravates nerve injury, but one of the important clinical complications of post-stroke is infection.

Infection is a major clinical manifestation of stroke patients $[4,5]$. It is reported that $23-65 \%$ of patients suffer from post-stroke infections, of which pneumonia and urinary tract infections are the most common [6-10], and pneumonia triples the risk of death within 30 days post-stroke [11]. Infection refers to the local tissue and systemic inflammatory response caused by the invasion of bacteria, viruses, fungi, parasites and other pathogens into the human body [4]. In normal case, inflammation is the body's defensive response which could promote tissue repair and functional normalization. However, inflammation induced by post-stroke infection seriously affects the prognosis of stroke, suggesting that peripheral inflammation signals can be transmitted to the central nervous system, which further aggravates neuroinflammation.

Until now, there is no systematic report on how systemic inflammation caused by peripheral infection aggravates the prognosis of stroke. We speculate that infection-induced peripheral inflammation overlaps with stroke-induced central inflammation, and systemic inflammation aggravates the prognosis of stroke by aggravating related inflammation pathways. Nylon filament middle cerebral artery occlusion (MCAO) is the most popular method to simulate clinical cerebral ischemia, which was established by Koizum and Longa in 1980s [12, 13]. Lipopolysaccharide (LPS) is a component of the cell wall of Gram-negative bacteria, which is a classical agent for inducing inflammation [14-16]. Therefore, we employed LPS to induce peripheral inflammatory, rat middle cerebral artery occlusion (MCAO) to simulate clinical ischemic stroke, and the Toll-Like Receptor Signaling Pathway PCR Array to detect 84 genes known to be involved in the pathways to clarify the overlap key point of peripheral inflammation aggravating central inflammation in the acute stage of experimental cerebral ischemia, and to preliminarily reveal the target of alternative therapy for reducing stroke infection. The flow chart of the present experiment was shown in Fig. 1. It is possible that LPS-induced peripheral inflammation overlaps with stroke-induced central inflammation, and LPS aggravates the prognosis of stroke by aggravating related

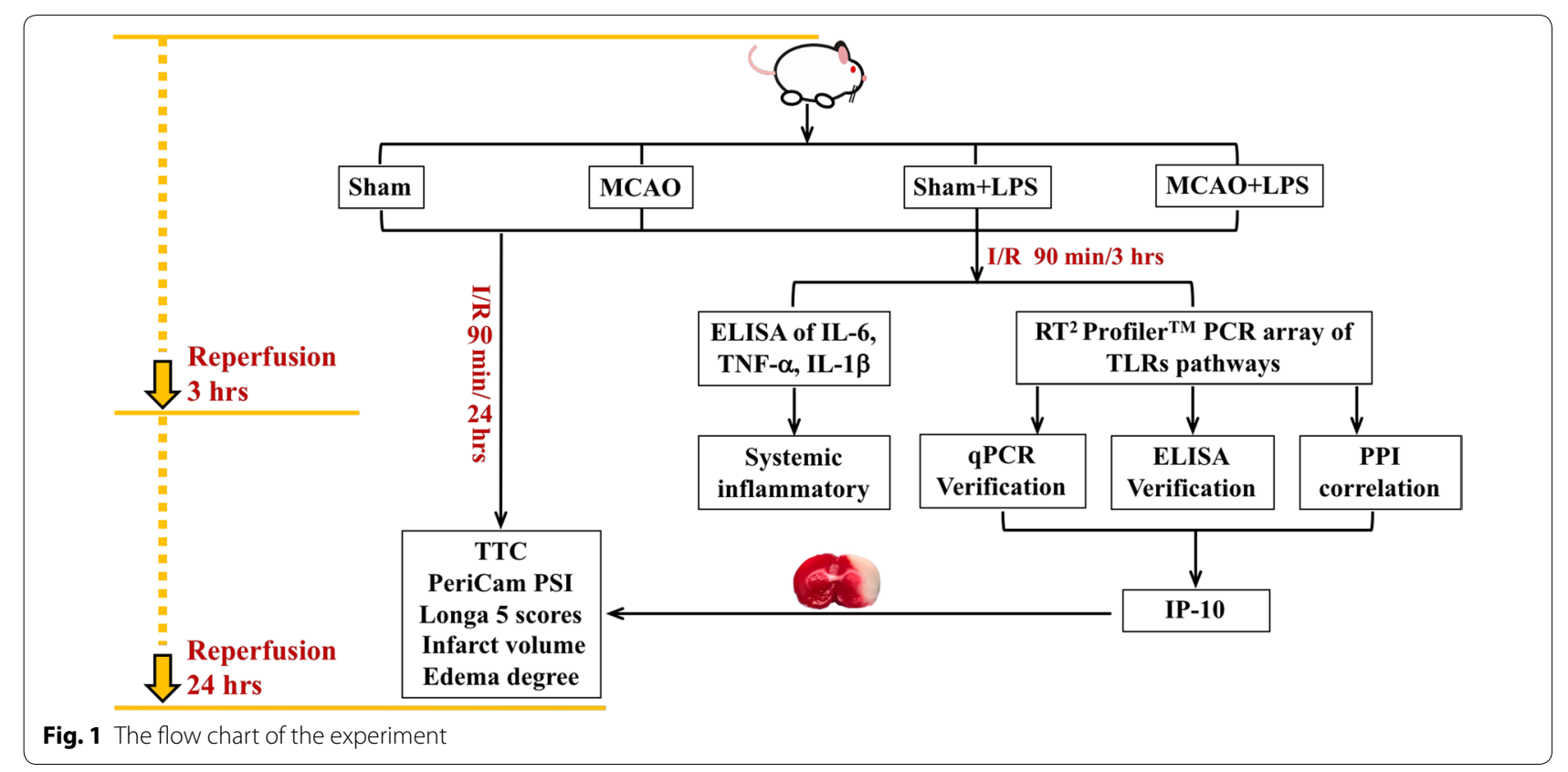


inflammation pathways, probably chemokine in the acute stage.

\section{Results}

\section{Reduction in cerebral blood perfusion}

The cerebral blood perfusion (CBP) was recorded before filament insertion, after filament insertion, and after filament pullout, at least 3 min each time. Figure 2a showed the axis top view of rat brain in chronological order. The skull showed slight white after filament insertion, suggesting ischemia in infarcted hemisphere. Figure $2 \mathrm{~b}$ showed bright red and a little yellow in both hemispheres before filament insertion, indicating rich and smooth CBP in the whole brain. After filament insertion, infarcted hemisphere showed blue color, suggesting significantly decrease in CBP of MCA. Then the CBP of infarcted hemisphere basically restored to the preoperative level after filament pullout, with no difference between contralateral and ipsilateral hemisphere. Figure $2 \mathrm{c}$ showed the variation curves of bilateral hemisphere and the whole brain in chronological order, and cerebral blood flow decreased significantly in infarcted side (red line). The exact CBP values were shown in Fig. $2 \mathrm{~d}$ and Table 1. Compared to the baseline, CBP of infarcted hemisphere was significantly decreased $37.57 \%$, suggesting that the rat MCAO model was successfully replicated.

\section{System inflammation induced by LPS worsens outcome after MCAO surgery}

To determine the effect of a systemic inflammatory stimulus on cerebral ischemia/reperfusion injury, rats were subjected to LPS intraperitoneal injection at doses of $40 \mu \mathrm{g} / 300 \mathrm{~g}$ rat $(134 \mu \mathrm{g} / \mathrm{kg})$ or $80 \mu \mathrm{g} / 300 \mathrm{~g}$ rat $(268 \mu \mathrm{g} / \mathrm{kg})$ immediately after sham or MCAO surgery and the extent of brain damage was evaluated
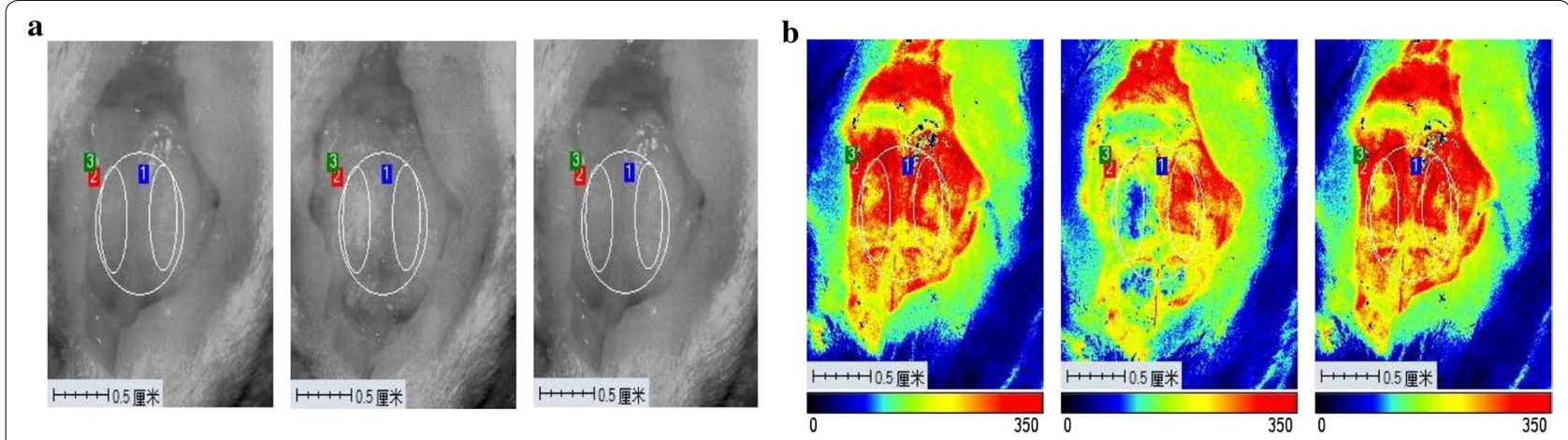

c
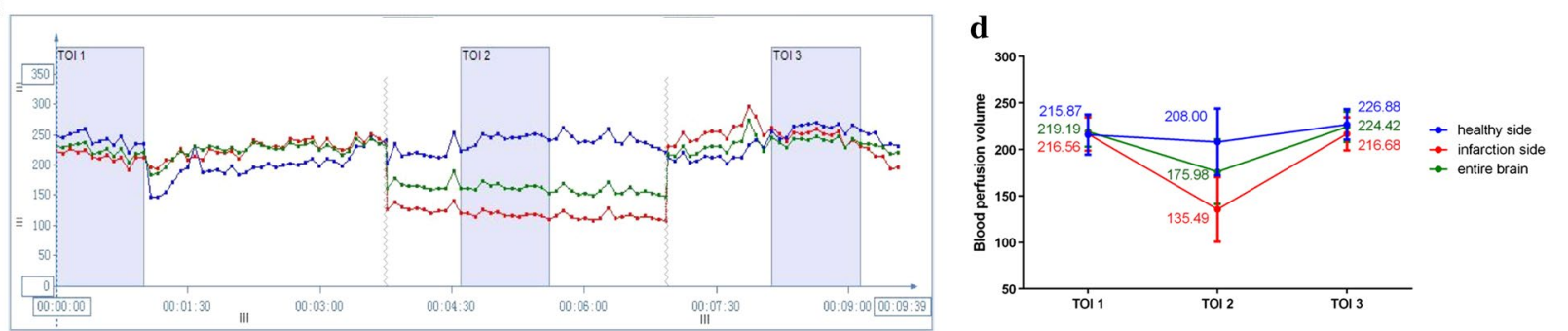

Fig. 2 The results of PeriCam PSI monitoring $(n=6)$. a The axis top view of rat brain; $\mathbf{b}$ The CBP of SD rat before, during and after surgery; $\mathbf{c}$ The cerebral blood flow curve of SD rat before, during and after surgery; $\mathbf{d}$ The variation values of cerebral blood flow in SD rats. (ROI 1 delineated the healthy side, ROI 2 infarcted side and ROI 3 the whole brain, corresponding to blue line, red line and green line respectively in the blood flow curve. TOl time of interest)

Table 1 The exact CBP values of bilateral hemisphere and the whole brain $(n=6)$

\begin{tabular}{llllr}
\hline Groups & Before surgery & After surgery & Filament pullout & Decrease rate of CBP \% \\
\hline Healthy hemisphere & $215.87 \pm 21.60$ & $208.00 \pm 35.93$ & $226.88 \pm 16.33$ & $3.33 \pm 5.98$ \\
Infarcted hemisphere & $216.56 \pm 17.92$ & $135.49 \pm 34.82^{* *}$ & $216.68 \pm 17.80^{\# \#}$ & $37.57 \pm 5.59$ \\
Whole brain & $219.19 \pm 16.25$ & $175.98 \pm 34.85^{* *}$ & $224.41 \pm 16.19^{\# \#}$ & $19.69 \pm 6.32$ \\
\hline
\end{tabular}

$\mathrm{P}<0.05^{*}, \mathrm{P}<0.01^{* *}$, compared with before surgery; $\mathrm{P}<0.05^{\#}, \mathrm{P}<0.01^{\# \#}$, compared with after surgery 
$24 \mathrm{~h}$ post-MCAO. No rats died during the whole procedure. The extent of brain damage was evaluated by neurological score, infarct volume and edema degree. $40 \mu \mathrm{g}$ LPS caused $12.9 \%, 29.58 \%$ and $55.63 \%$ increase in neurological score, infarct volume and edema degree respectively compared with vehicle treatment. $80 \mu \mathrm{g}$ LPS caused $29.0 \%, 60.21 \%$ and $56.62 \%$ increase in neurological score, infarct volume and edema degree respectively compared with vehicle treatment (Table 2 and Fig. 3). The aggravated injury was mostly attributable to exacerbation of cortical damage (Fig. 3d, e), and significantly increased the severity of neurological deficit. Moreover, the infarct site caused by $80 \mu \mathrm{g}$ LPS was more uniform and thorough, but the edema degree was similar compared with that of $40 \mu \mathrm{g}$ LPS. Therefore, $80 \mu \mathrm{g}$ LPS was selected as the dosage in the following experiments.

Table 2 The extent of brain damage in each group $(n=10)$

\begin{tabular}{lllll}
\hline Groups & $\mathbf{n}$ & Neurological score & Infarct volume \% & Edema degree \% \\
\hline Sham & 10 & 0 & 0 & 0 \\
Sham $+40 \mu \mathrm{g}$ LPS & 10 & 0 & 0 & 0 \\
Sham $+80 \mu \mathrm{g}$ LPS & 10 & 0 & 0 & 0 \\
MCAO & 10 & $1.55 \pm 0.50^{* *}$ & $14.20 \pm 3.09^{* *}$ & $7.10 \pm 1.77^{* *}$ \\
MCAO $+40 \mu \mathrm{g}$ LPS & 10 & $1.75 \pm 0.35^{* *}$ & $18.40 \pm 3.52^{* * \#}$ & $11.05 \pm 2.45^{* * \# \#}$ \\
MCAO $+80 \mu \mathrm{g}$ LPS & 10 & $2.00 \pm 0.00^{* * \#}$ & $22.75 \pm 2.17^{* * \# \#}$ & $11.12 \pm 2.46^{* * \# \#}$ \\
\hline
\end{tabular}

$\mathrm{P}<0.05^{*}, \mathrm{P}<0.01^{* *}$ compared with Sham group; $\mathrm{P}<0.05^{\#}, \mathrm{P}<0.01^{\# \#}$, compared with MCAO group
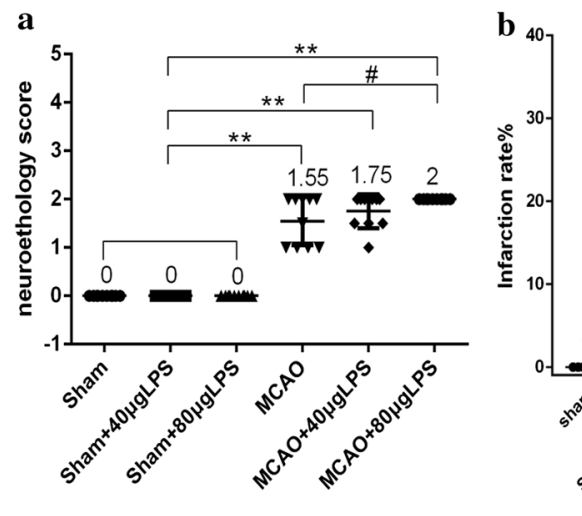

d

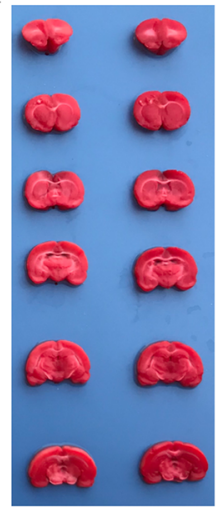

Sham

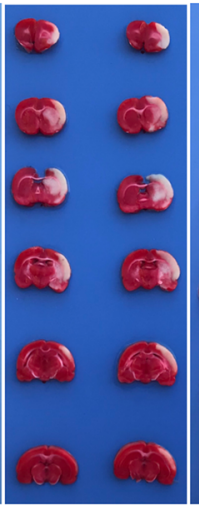

MCAO

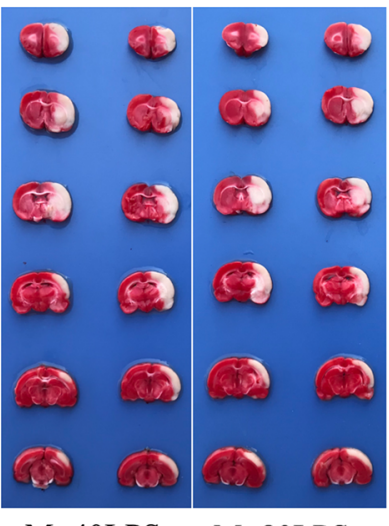

M+40LPS M+80LPS
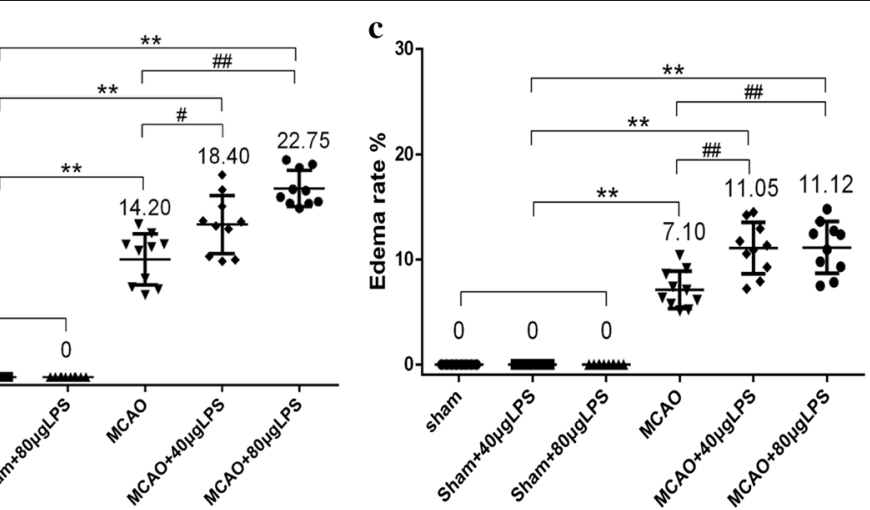

e
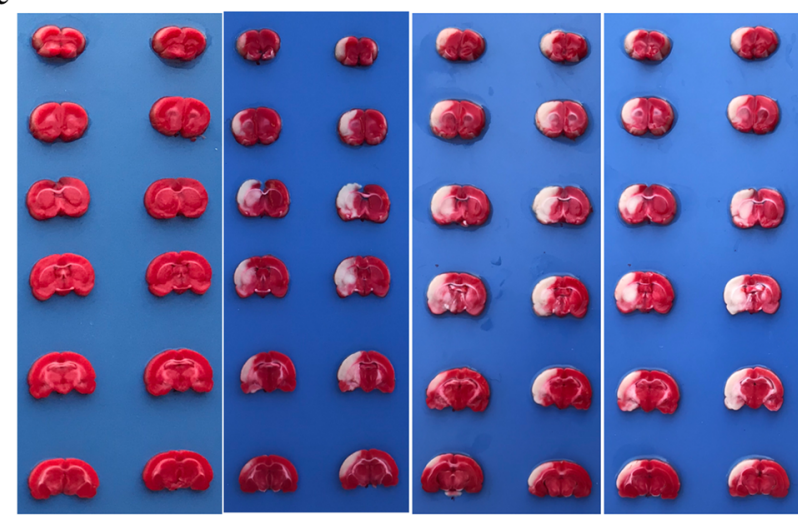

Sham

MCAO

M+40LPS M+80LPS

Fig. 3 Systemic LPS exacerbates the extent of brain damage $(n=10)$. a LPS increased the neurological score; $\mathbf{b}$ LPS increased the infarct volume; $\mathbf{c}$ LPS increased the edema degree; $\mathbf{d}$ Infarction volume detected by TTC staining (the frontal sides); $\mathbf{e}$ Infarction volume detected by TTC staining (the reverse sides). $\left(P<0.05^{*}, P<0.01^{* *}\right.$ compared with Sham group; $P<0.05^{\#}, P<0.01^{\# \#}$, compared with MCAO group.) 


\section{System inflammation induced by LPS are dominated} by different circulating cytokines

To investigate the systemic inflammatory responses in actuate state, we investigated the plasma levels of three key cytokines $4.5 \mathrm{~h}$ post-MCAO, that was also after $4.5 \mathrm{~h}$ of LPS administration. LPS induced profound increases in IL- 6 and IL- $1 \beta$ in both $80 \mu \mathrm{g}$ LPS administrated groups. The level of IL-6 increased 3.00fold in Sham + LPS group, 3.65-fold in MCAO+LPS group compared with that in Sham group (Fig. 4a). The level of IL-1 $\beta$ increased 6.51-fold in Sham + LPS group, 7.41-fold in MCAO+LPS group compared with that in Sham group (Fig. 4c). The systemic inflammatory responses caused by $\mathrm{MCAO}$ seemed not serious in the

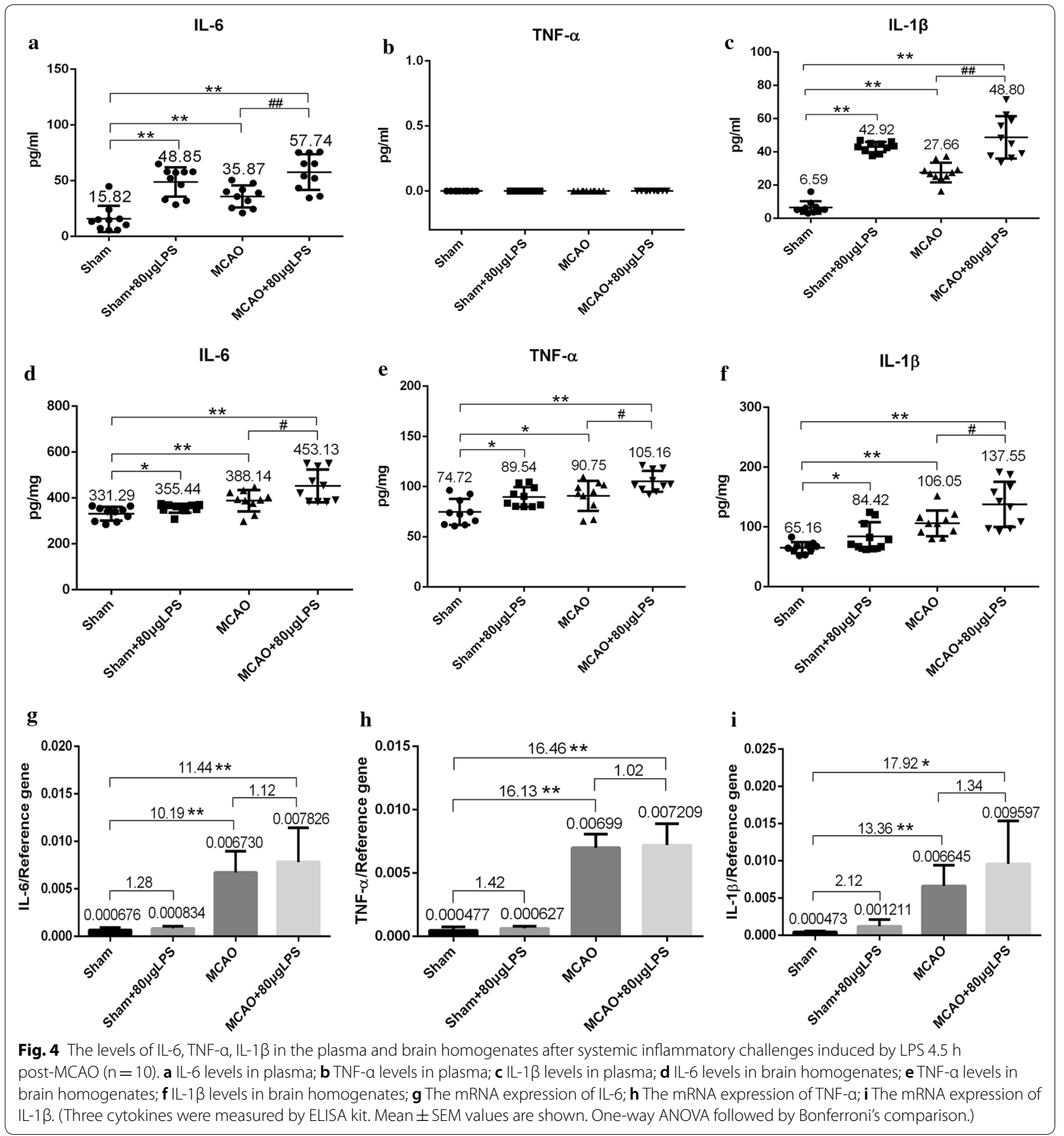


early stage $(4.5 \mathrm{~h})$, as the level of IL- 6 and IL-1 $\beta$ was only 2.27-fold and 4.20-fold compared with that in Sham group. While no TNF- $\alpha$ was detected (Fig. $4 \mathrm{~b}$ ).

Simultaneously, we also investigated the brain homogenates levels of three key cytokines $4.5 \mathrm{~h}$ post-MCAO. MCAO induced profound increase in IL-6, TNF- $\alpha$, IL- $1 \beta$ and LPS aggravated the local inflammation in the brain. The level of IL-6 increased 1.17-fold in MCAO group, 1.37-fold in MCAO + LPS group compared with that in Sham group (Fig. 4d). The level of TNF- $\alpha$ increased 1.21fold in MCAO group, 1.41-fold in MCAO+LPS group compared with that in Sham group (Fig. 4e). The level of IL-1 $\beta$ increased 1.63-fold in MCAO group, 2.11-fold in $\mathrm{MCAO}+\mathrm{LPS}$ group compared with that in Sham group (Fig. 4f). LPS alone also induced local inflammation in the brain to a small extent, as the levels of IL- 6 , TNF- $\alpha$, IL-1 $\beta$ were 1.07 -fold, 1.20 -fold and 1.30 -fold respectively compared with that in Sham group.

\section{Differential gene expression in experimental cerebral ischemia}

To get insight into the mechanism of more serious cerebral injury induced by LPS, we detected 84 genes involved in Toll-Like receptor signaling pathway $4.5 \mathrm{~h}$ post-MCAO. The data in details was shown in Table 3 and Fig. 5a. LPS alone didn't caused significant changes after administrated to Sham group, as no genes had significant 1.5 -fold changes. Twenty-five genes were upregulated more than 1.5-fold after subjected to $\mathrm{MCAO}$ surgery and chemokine $(\mathrm{C}-\mathrm{C}$ motif) ligand $2(\mathrm{Ccl} 2)$ had the greatest changes in expression as 41.26 -fold. Twentythree genes had up-regulated more than 1.5-fold after subjected to MCAO + LPS and colony stimulating factor 3 (Csf3) had the greatest changes in expression as 49.21fold. Interestingly, when we compared with MCAO and $\mathrm{MCAO}+\mathrm{LPS}$ group, we found that 8 genes were upregulated but only chemokine ( $\mathrm{C}-\mathrm{X}-\mathrm{C}$ motif) ligand 10 (CXCL10) had significant 1.64-fold expression (Fig. 5b). The expression of IL- 6 , TNF- $\alpha$, IL- $1 \beta$ were $1.28-$, $1.42-$ and 2.12-fold changes respectively in Sham + LPS group compared with that in Sham group, but without significant differences. The expression of IL- 6, TNF- $\alpha$, IL- $1 \beta$ in $\mathrm{MCAO}$ or MCAO + LPS group was significantly up-regulated compared with that in Sham group (Fig. 4g-i).

To confirm the expression of CXCL 10, we employed real-time PCR technique to quantitate its mRNA level. As shown in Fig. 6a, the mRNA level of CXCL 10 in Sham + LPS, MCAO and MCAO + LPS group was significant 4.36-fold, 8.31-fold and 14.73-fold changes respectively compared with that in Sham group. Moreover, LPS caused significant 1.77-fold change after subjected to MCAO surgery. The results corresponded to those of PCR array as shown in Fig. 6b. The expression of CXCL 10 in Sham + LPS, MCAO and MCAO+LPS group was 3.75-, 6.98- and 11.41-fold changes respectively compared with that in Sham group and 1.64-fold change between MCAO and MCAO + LPS group.

\section{GO enrichment analysis}

To investigate the functional changes in the pathological course of MCAO and MCAO + LPS, the 27 different genes between MCAO vs Sham or MCAO + LPS vs Sham were mapped to DAVID database. This project provided three structured networks of defined terms to describe the gene product attributes: Biological process (BP), molecular function (MF) and cellular compartment (CC). The 27 different genes were up-regulated in the MCAO or MCAO+LPS group $4.5 \mathrm{~h}$ post-MCAO. The different genes were most commonly associated with BP, including immune response, inflammatory response, response to wounding and etc. (Table 4).

\section{PPI network construction}

The 27 different genes between MCAO vs Sham or MCAO+LPS vs Sham were imported to STRING database to construct the PPI network. Betweenness refers to the number of edges passing through the node. Closeness calculates the total distance to other nodes. The degree is the node number directly connecting with target node in the network. A higher value for the degree indicates a tight connected network and is likely to more robust. A total of 25 genes were screen with degree $>5$, two genes (Clec4e and Tlr1) with degree 0 , indicating both of them had no relationship with others (Table 5). Interesting, the degrees of IL-6, TNF- $\alpha$, IL- $1 \beta$ were $\geq 21$ and in the top three order, suggesting they may have an important role in $\mathrm{MCAO}$ and MCAO + LPS induced cerebral injury. The degree of CXCL 10 were 14, that was 14 genes were directly connecting with CXCL 10. The PPI network was shown in Fig. 4c, the green nodes represented the genes that directly connecting with CXCL 10, the others indirectly connecting. The green nodes in the left side were also directly connecting with $\mathrm{Cd} 14$, which was closely related to the function of LPS.

We also construct the PPI network of the eight genes which up-regulated in MCAO + LPS group compared with that MCAO group. Except for Tlr 1, the other seven genes were connected with each other. The degrees of IL- 6 , TNF- $\alpha$, IL- $1 \beta$ were 6 , and also in the top three order. CXCL 10 as the only significantly upregulated gene was directly connecting with five genes (Fig. 4d and Table 6). 


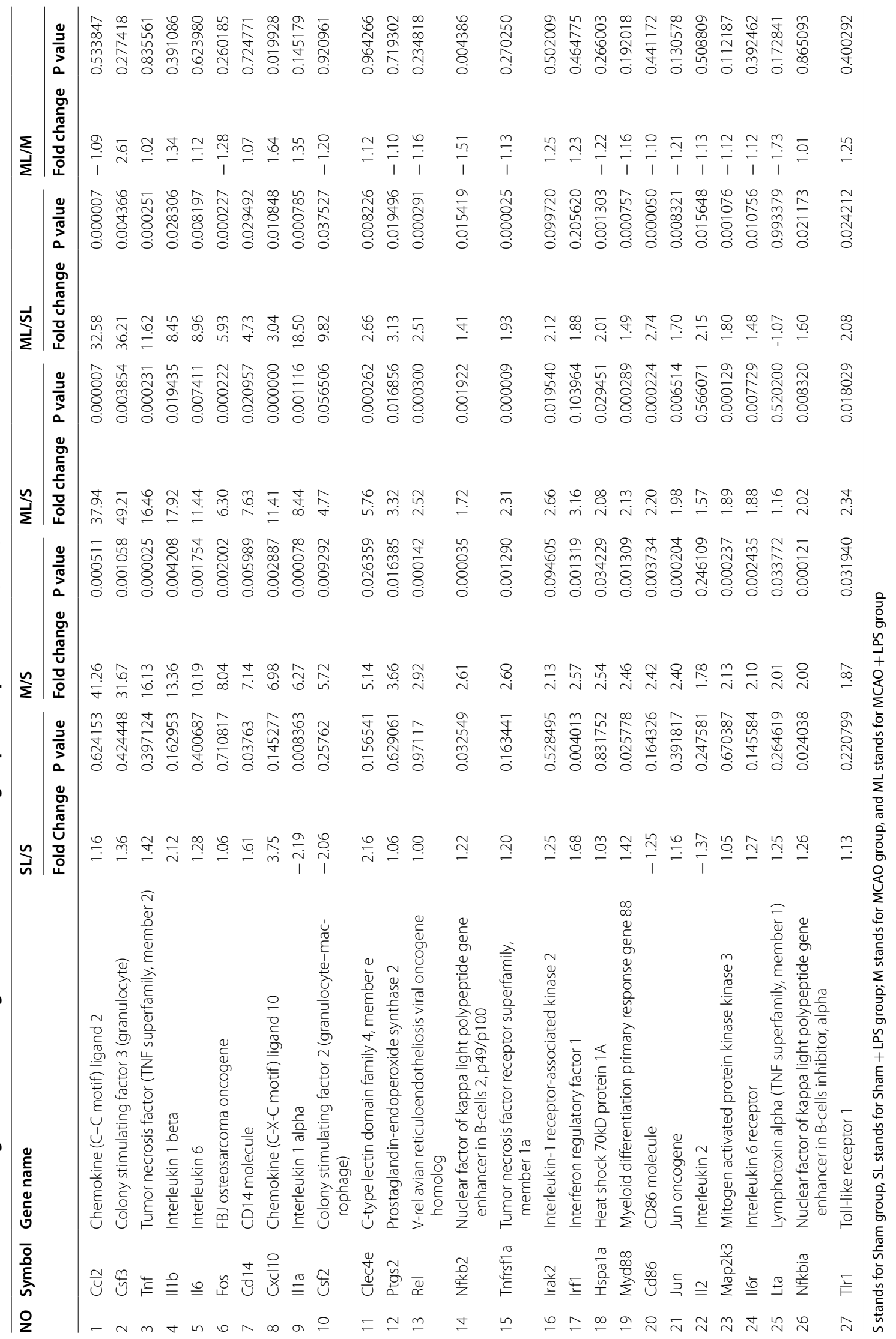



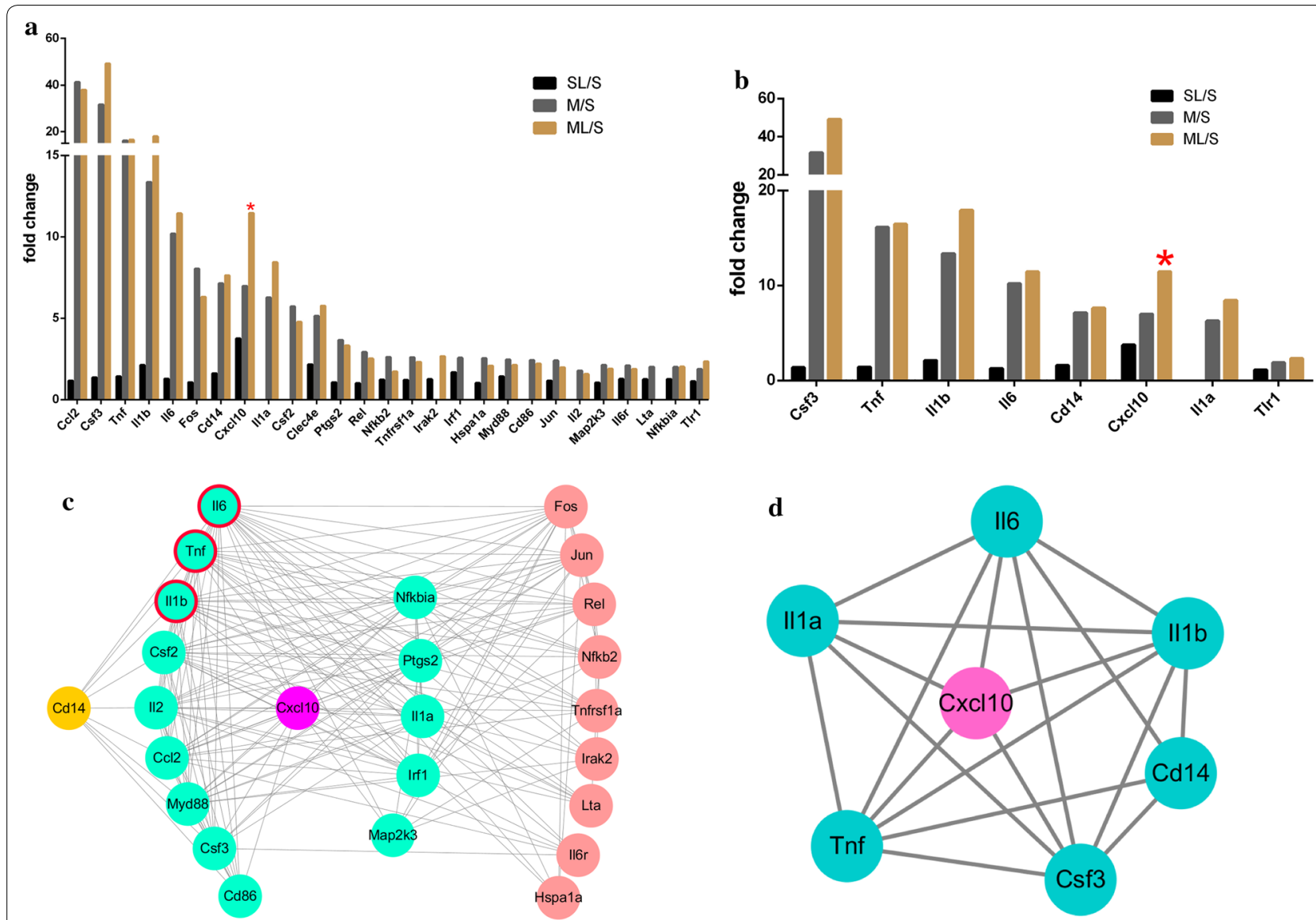

Fig. 5 The fold changes and PPI network of different genes. a The fold changes of 27 different genes in different groups $(n=4)$. $\mathbf{b}$ The fold changes of 8 up-regulated genes in MCAO + LPS group compared with that in MCAO group $(n=4)$. c The PPI network of 27 different genes in MCAO or $\mathrm{MCAO}+$ LPS group compared with that in Sham group. $\mathbf{d}$ The PPI network of 8 up-regulated genes in MCAO + LPS group compared with that in MCAO group. (c The green nodes directly connected with $\mathrm{Cxcl} 10$, and the green nodes in the left side also directly connected with $\mathrm{Cd} 14$ which was associated with LPS function. The pink nodes indirectly connected with Cxcl 10; d Cxcl 10 directly connected with five nodes. S stands for Sham group, SL stands for Sham + LPS group; M stands for MCAO group, and ML stands for MCAO + LPS group.)

\section{Increased levels of CXCL10 in brain homogenates and plasma}

The production of CXCL10 in brain homogenates and plasma was measured by ELISA kit according to the manufactures protocol. The levels of CXCL 10 in three treated groups were significantly higher than that in Sham group, and highest in MCAO + LPS group as $3505.07 \mathrm{pg} / \mathrm{mg}$ and $483.88 \mathrm{pg} / \mathrm{ml}$, no matter in brain homogenates or plasma (Fig. 6c, d). Moreover, the levels in brain homogenates were generally ten times higher than that in plasma.

\section{Discussion}

In the present study, we firstly provide the evidence that LPS (134 and $268 \mu \mathrm{g} / \mathrm{kg}$ ) aggravated the neurological score, cerebral infarction area and edema rate after rat experimental cerebral ischemia $24 \mathrm{~h}$, and the damage caused by $268 \mu \mathrm{g} / \mathrm{kg}$ was more uniform and stable. Then we focused on the acute stage (I/R $90 \mathrm{~min} / 3 \mathrm{~h}$ ) to explore the stacking point of peripheral inflammation and central inflammation in order to find alternative therapeutic targets for stroke infection from the source. The plasma levels of inflammatory cytokines could reflect the systemic inflammatory response induced by LPS and the spread of central inflammation to the peripheral. IL-6 and IL-1 $\beta$ were both responded to LPS or MCAO, and the response induced by LPS was more profound, 3.00fold and 6.51-fold respectively in Sham + LPS group compared with that in Sham group (Fig. $4 \mathrm{a}-\mathrm{c}$ ), suggesting LPS successfully induced system inflammatory. The peripheral inflammatory response (plasma levels of IL- 6 and IL-1 $\beta$ ) induced by MCAO was not seriously increased compared with that induced by LPS only, but it was responded much more profoundly in the brain homogenate (Fig. 4d-f), suggesting the inflammatory response induced by $\mathrm{MCAO}$ was concentrated in the cerebral ischemia parts at the acute stage. Plasma TNF- $\alpha$ 

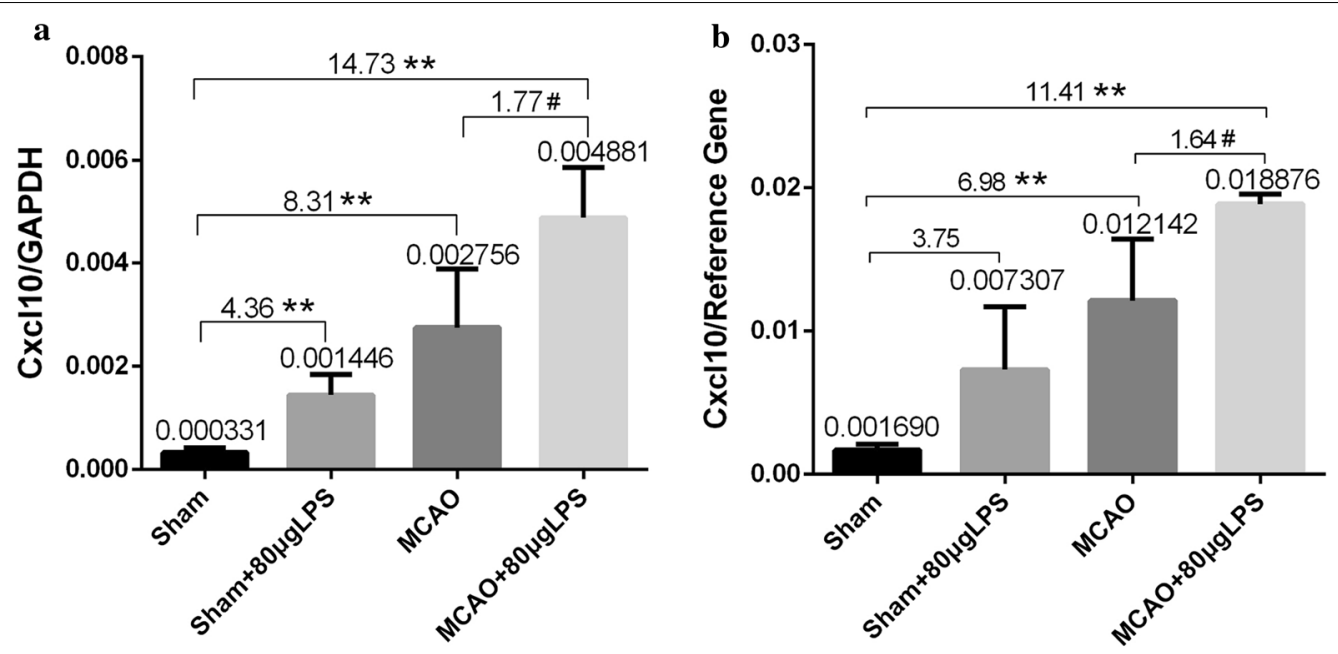

IP-10
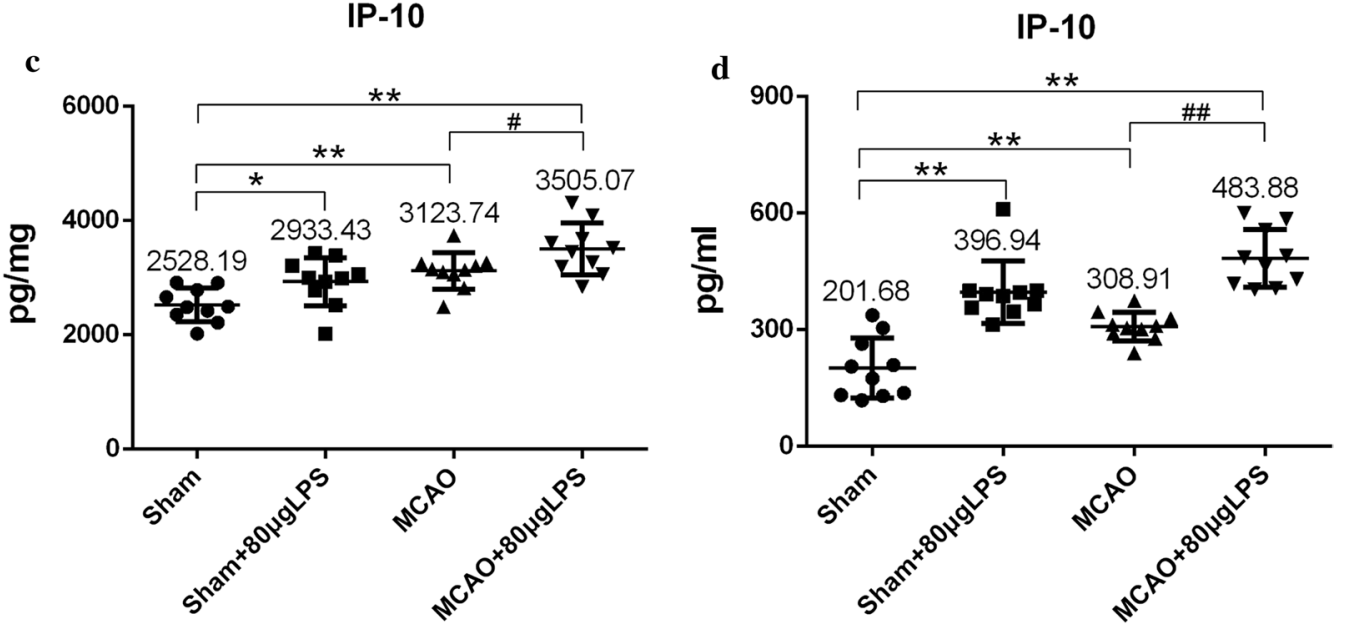

Fig. 6 The mRNA level of $C x C l 10$ and contents of IP-10 in different groups. a The mRNA level of Cxcl 10 detected by real-time PCR technique $(n=4)$. b The mRNA level of $C x C l 10$ detected by PCR array respectively $(n=4)$. c The IP 10 levels in the brain homogenates measured by ELISA kit $(\mathrm{n}=10)$. $\mathbf{d}$ The IP 10 levels in the plasma measured by ELISA kit $(n=10)$

had no response to LPS or MCAO stimulation in the acute stage, which was consistent to the report by Yousuf [17]. The LPS administration after MCAO surgery was both aggravated the central and peripheral inflammatory responses, although the dosage was only $268 \mu \mathrm{g} / \mathrm{kg}$. The dosage of LPS used for inducing rat inflammation was usually milligram level per kilogram [18-22], which were much higher than the dosage we used. Trace LPS, as the last straw to crush the camel, could significantly aggravate ischemia brain injury post-MCAO, which explained the high mortality rate in stroke infection patients from the experimental level.

Systemic inflammatory response was successfully induced after $4.5 \mathrm{~h}$ LPS intraperitoneal injection and LPS aggravated brain damage after MCAO surgery. To get insight into the mechanism of more serious cerebral injury induced by LPS, we employed $\mathrm{RT}^{2}$ Profiler $^{\mathrm{TM}}$
PCR array to detect the 84 genes expression of Tolllike Receptor Signaling Pathway in the infarcted hemisphere, high-throughput screening the specific genes of stroke infection in the acute stage in order to reveal the possible alternative target. The genes expression of both MCAO and MCAO + LPS group has changed significantly (Table 3 and Fig. 5a), and eight genes were upregulated in MCAO + LPS group compared with that in MCAO group, but only CXCL 10 had significant higher expression (Fig. 5b). CXCL 10 was also in an important position with degrees of $\geq 14$ in PPI network (Fig. 5c, d), corresponding to the report by Quan [23]. To confirm the expression of CXCL 10, we employed real-time PCR technique to quantitate its mRNA level (Fig. 6a, b) and ELISA kit to detect the increased contents of CXCL 10 in brain homogenates and plasma from the protein level (Fig. 6c, d). 
Table 4 The significantly enriched GO terms with a high count of different genes $4.5 \mathrm{~h}$ post-MCAO

\begin{tabular}{|c|c|c|c|c|}
\hline Term & Category & Description & Count & P-value \\
\hline GO:0006955 & $\mathrm{BP}$ & Immune response & 15 & $9.38 \mathrm{E}-15$ \\
\hline GO:0006954 & $\mathrm{BP}$ & Inflammatory response & 12 & $7.31 \mathrm{E}-14$ \\
\hline GO:0009611 & $\mathrm{BP}$ & Response to wounding & 12 & $8.33 \mathrm{E}-12$ \\
\hline GO:0006952 & $\mathrm{BP}$ & Defense response & 12 & $1.30 \mathrm{E}-10$ \\
\hline GO:0010604 & $\mathrm{BP}$ & Positive regulation of macromolecule metabolic process & 12 & $5.05 \mathrm{E}-09$ \\
\hline GO:0045449 & $\mathrm{BP}$ & Regulation of transcription & 12 & 0.001056 \\
\hline GO:0010557 & $\mathrm{BP}$ & Positive regulation of macromolecule biosynthetic process & 11 & $1.44 \mathrm{E}-08$ \\
\hline GO:0042127 & $\mathrm{BP}$ & Regulation of cell proliferation & 11 & $1.67 \mathrm{E}-08$ \\
\hline GO:0031328 & $\mathrm{BP}$ & Positive regulation of cellular biosynthetic process & 11 & $2.13 \mathrm{E}-08$ \\
\hline GO:0009891 & $\mathrm{BP}$ & Positive regulation of biosynthetic process & 11 & $2.32 \mathrm{E}-08$ \\
\hline MF00016 & MF & Signaling molecule & 11 & $1.78 \mathrm{E}-07$ \\
\hline GO:0001817 & $\mathrm{BP}$ & Regulation of cytokine production & 10 & $1.68 \mathrm{E}-12$ \\
\hline GO:0005615 & CC & Extracellular space & 10 & $3.33 \mathrm{E}-08$ \\
\hline GO:0010628 & $\mathrm{BP}$ & Positive regulation of gene expression & 10 & $1.13 \mathrm{E}-07$ \\
\hline GO:0044421 & CC & Extracellular region part & 10 & $1.15 \mathrm{E}-06$ \\
\hline GO:0005576 & $\mathrm{CC}$ & Extracellular region & 10 & $5.80 \mathrm{E}-04$ \\
\hline GO:0006355 & $\mathrm{BP}$ & Regulation of transcription, DNA-dependent & 10 & 7.87E-04 \\
\hline GO:0051252 & $\mathrm{BP}$ & Regulation of RNA metabolic process & 10 & $8.82 \mathrm{E}-04$ \\
\hline MF00017 & MF & Cytokine & 9 & $3.90 E-12$ \\
\hline GO:0045893 & $\mathrm{BP}$ & Positive regulation of transcription, DNA-dependent & 9 & 4.94E-07 \\
\hline
\end{tabular}

GO Gene Ontology, BP biological process, CC cellular compartment, $M F$ molecular function

CXCL10 also known as interferon gamma-induced protein 10 (IP-10), whose specific receptor is C-X-C chemokine receptor 3 (CXCR3). CXCL 10, as the name suggested, is chemotactic cytokine, belonging to $\alpha$-chemokine family. Chemokine controls the attraction of leukocytes to tissues, which is essential for inflammation and the host response to infection. Chemokines are thought to provide the signals that convert the lowaffinity, selectin-mediated interaction into the higheraffinity, integrin-mediated interaction that leads to extravasation of leukocytes [3]. Therefore, chemokines are necessary in the activation of immune cells and the transport of peripheral immune cells across the bloodbrain barrier. Microglia are the resident macrophage population of the CNS which could be activated by any type of brain pathology and migrate to the injury site. The chemokine IP-10 is expressed in neurons responding to ischemic brain injury and is a signaling candidate for activating microglia and directing them to the lesion site. It was reported that CXCR3, the specific receptor for IP-10, up-regulated in microglia and controlled microglial migration [24]. It has been reported that IP-10/CXCR3 had an important part in the pathological process of stroke patients $[25,26]$ and experimental cerebral ischemia [27-31]. The mRNA and protein expression of IP-10/CXCR3 was increased in a timedependent manner after permanent occlusion of the middle cerebral artery, suggesting IP-10/CXCR3 may be a potential novel therapeutic target in focal stroke [32, 33]. That's exactly what have happened. Chemokines and chemokine receptors, as a new target of stroke treatment, have been paid much more attention, and both CXC and CC chemokines as candidate drugs have been under research development [34]. At present, we just got the preliminary results that LPS worsened the prognosis of experimental cerebral ischemia via IP-10 recruit in the acute stage. Subsequently, we plan to design inhibitor experiment of CXCR3 in order to tamp the proinflammatory effect of IP-10. If we get the positive results, CXCR3 may be the possible target for both stroke and stroke-infection.

\section{Conclusions}

Taken together, it was possible that trace LPS aggravated the ischemic brain injury by induction of excessive IP-10 secretion in the acute stage, leading to excessive inflammation in the brain tissue, which consequently increased the infarct volume and edema degree $24 \mathrm{~h}$ post-MCAO. Chemokine IP-10 may be a diagnostic or prognostic biomarker (significantly increased in plasma) in ischemic stroke-infection and its specific receptor CXCR3 may be the alternative targets for stroke-infection therapy in the near future. 
Table 5 The details about PPI network of 27 different genes

\begin{tabular}{|c|c|c|c|c|}
\hline No & Name & Degree & $\begin{array}{l}\text { Betweenness } \\
\text { centrality }\end{array}$ & Closeness centrality \\
\hline 1 & 116 & 24 & 0.09513658 & 1 \\
\hline 2 & Tnf & 22 & 0.05768834 & 0.92307692 \\
\hline 3 & $\| 1 b$ & 21 & 0.04059896 & 0.888888889 \\
\hline 4 & Csf2 & 21 & 0.03921008 & 0.88888889 \\
\hline 5 & 112 & 20 & 0.03323299 & 0.85714286 \\
\hline 6 & $\mathrm{Ccl} 2$ & 19 & 0.02477026 & 0.82758621 \\
\hline 7 & Nfkbia & 18 & 0.0268796 & 0.8 \\
\hline 8 & Myd88 & 17 & 0.01976428 & 0.77419355 \\
\hline 9 & Fos & 16 & 0.02109266 & 0.75 \\
\hline 10 & Ptgs2 & 16 & 0.01153843 & 0.75 \\
\hline 11 & Jun & 15 & 0.015889 & 0.72727273 \\
\hline 12 & $\| 1 a$ & 14 & 0.01154667 & 0.70588235 \\
\hline 13 & Csf3 & 14 & 0.00856028 & 0.70588235 \\
\hline 14 & Cxcl10 & 14 & 0.01107399 & 0.70588235 \\
\hline 15 & Irf1 & 14 & 0.00318066 & 0.70588235 \\
\hline 16 & Rel & 13 & 0.00255087 & 0.68571429 \\
\hline 17 & Nfkb2 & 12 & 0.00695873 & 0.66666667 \\
\hline 18 & Tnfrsfia & 11 & 0.00973399 & 0.64864865 \\
\hline 19 & Cd86 & 10 & 4.03E-04 & 0.63157895 \\
\hline 20 & Cd14 & 9 & 0 & 0.61538462 \\
\hline 21 & Irak2 & 7 & 0.00366201 & 0.58536585 \\
\hline 22 & Lta & 7 & $4.53 \mathrm{E}-04$ & 0.58536585 \\
\hline 23 & Map2k3 & 7 & 0.00535152 & 0.58536585 \\
\hline 24 & $\| 6 r$ & 6 & 0 & 0.57142857 \\
\hline 25 & Hspa1a & 5 & 0 & 0.55813953 \\
\hline 26 & Clec4e & 0 & 0 & 0 \\
\hline 27 & Tlr1 & 0 & 0 & 0 \\
\hline
\end{tabular}

Table 6 The details about PPI network of eight different genes

\begin{tabular}{lllll}
\hline No & Name & Degree & $\begin{array}{l}\text { Betweenness } \\
\text { centrality }\end{array}$ & Closeness centrality \\
\hline 1 & II6 & 6 & 0.03333333 & 1 \\
2 & Tnf & 6 & 0.03333333 & 1 \\
3 & II1 & 6 & 0.03333333 & 1 \\
4 & Csf3 & 6 & 0.03333333 & 1 \\
5 & Cxcl10 & 5 & 0 & 0.85714286 \\
6 & II1 & 5 & 0 & 0.85714286 \\
7 & Cd14 & 4 & 0 & 0.75 \\
8 & Tlr1 & 0 & 0 & 0 \\
\hline
\end{tabular}

\section{Methods}

Animals

All procedures were approved by the Medicine Ethics Review Committee for animal experiments of the China
Academy of Chinese Medical Sciences, and all efforts were made to minimize suffering of rats. Sprague-Dawley rats (specific pathogen-free grade, Certificate No. 20100034), weighing $300 \pm 20$ g, 8 weeks old, were used for the study, which were purchased from Vital River Laboratory Animal Technology Co., Ltd. (Beijing, China). Male rats were used in the initial study because estrogen was known to protect against ischemic injury [35-37]. However, future studies with female rats will have to be conducted to assess potential sex-dependent effects on the inflammatory response after MCAO. The animal experiment was carried out in Clean Grade Animal Center of Institute of Chinese Materia Medica, China Academy of Chinese Medical Sciences. The rats were housed in a controlled environment $\left(21 \pm 1{ }^{\circ} \mathrm{C}\right.$ temperature, $55 \pm 10 \%$ relative humidity) with a 12/12-h light/dark cycle and free access to water and standard diet. The sample size was calculated by a power analysis and previous inflammation studies of the MCAO model [38-40]. The rats were allowed to acclimate for 7 days before the experiment. Sixty rats were randomly divided into six groups with ten in each one, that was Sham group, Sham $+40 \mu \mathrm{g}$ LPS group, Sham $+80 \mu \mathrm{g}$ LPS group, MCAO group, $\mathrm{MCAO}+40 \mu \mathrm{g}$ LPS group, and $\mathrm{MCAO}+80 \mu \mathrm{g}$ LPS group.

\section{Transient focal cerebral ischemia}

Transient focal cerebral ischemia was induced using the intraluminal filament model of MCAO, which was firstly described by Koizumi [12] and Longa [13] in 1980s. Briefly, rats were anesthetized with $1.5-2.0 \%$ isoflurane (Beijing ZS Dichuang Technology Development Co., Ltd., Beijing, China) using respiratory anesthesia machine (ZSMV, Beijing ZS Dichuang Technology Development Co., Ltd., Beijing, China), and fixed on homeothermic electric blanket $\left(37 \pm 0.5^{\circ} \mathrm{C}\right)$ throughout surgery until coming around. Nylon filament (tip diameter $0.38 \pm 0.02 \mathrm{~mm}$, polylysine coated) was inserted into the right external carotid artery (ECA), and advanced through the internal carotid artery (ICA) until it obstructed the MCA. Reperfusion was performed after 90 min occlusion in anesthetic state. Sham surgery was performed exactly the same as above, but the filament was immediately withdrawn after reaching the origin of the MCA. Following $\mathrm{MCAO}$, rats were placed in temperature-controlled $\left(37 \pm 1.0^{\circ} \mathrm{C}\right)$ recovery cages for $2 \mathrm{~h}$ to prevent post-surgery hypothermia. The order in which rats from different groups were subjected to MCAO was randomized.

\section{Neurological function assessment}

Rats were evaluated for neurologic deficits $24 \mathrm{~h}$ after reperfusion (ischemia $90 \mathrm{~min}$ reperfusion for $24 \mathrm{~h}, \mathrm{I} / \mathrm{R}$ $90 \mathrm{~min} / 24 \mathrm{~h}$ ) according to Longa 5 scores [2] by a fixed 
investigator who was blind to the groups. The scoring criteria are as follows: $0=$ no deficit; $1=$ failure to fully extend left forepaw, mild neurological deficit; $2=$ circling to the left, moderate neurological deficit; $3=$ falling to the left, severe neurological deficit; $4=$ unable to walk spontaneously, conscious loss. This method is suitable for early stage of MCAO, within 7 days after surgery. The rats with 0 value in MCAO or MCAO+LPS group were eliminated and euthanized with intraperitoneal injection of $3 \%$ pentobarbital sodium salt (Sigma, USA) at $0.5 \mathrm{ml} / 100 \mathrm{~g}$.

\section{Measurement of infarct volume and edema degree}

Rats were anaesthetized with I.P. of $1 \%$ pentobarbital sodium salt. Brains were frozen on dry ice and serially sectioned into six coronal slices $(2 \mathrm{~mm})$ with brain mold. The brain slices were stained with $2 \%$ triphenyl tetrazolium chloride (TTC) at $37^{\circ} \mathrm{C}$ for $15 \mathrm{~min}$ in the dark and fixed with $4 \%$ paraformaldehyde overnight. The infarct volume corrected for swelling, and edema degree were quantified using Image ProPlus Software by a fixed investigator who was blind to the groups, using the following formula [41-43]:

$$
\begin{aligned}
& \text { Infarct rate } \%=\frac{\mathrm{CoV}-\mathrm{IpV}}{2 \mathrm{CoV}} 100 \% ; \\
& \text { Edema rate } \%=\frac{\mathrm{IpV}+\mathrm{InV}-\mathrm{CoV}}{2 \mathrm{CoV}} 100 \% ;
\end{aligned}
$$

CoV: contralateral hemisphere volume; IpV: ipsilateral no infarct volume; InV: infarct volume as shown in Fig. 7.

\section{Real-time cerebral blood perfusion}

Cerebral blood perfusion (CBP) was dynamically and instantly monitored using Pericam Perfusion Speckle Image (PeriCam PSI) system by a fixed investigator who was blind to the groups, which could display the image and blood flow curve at the same time [44, 45]. The rats lied prone on an homeothermic electric blanket $\left(37 \pm 0.5{ }^{\circ} \mathrm{C}\right)$ under anesthesia. Head median incision was made to expose the entire parietal bone and

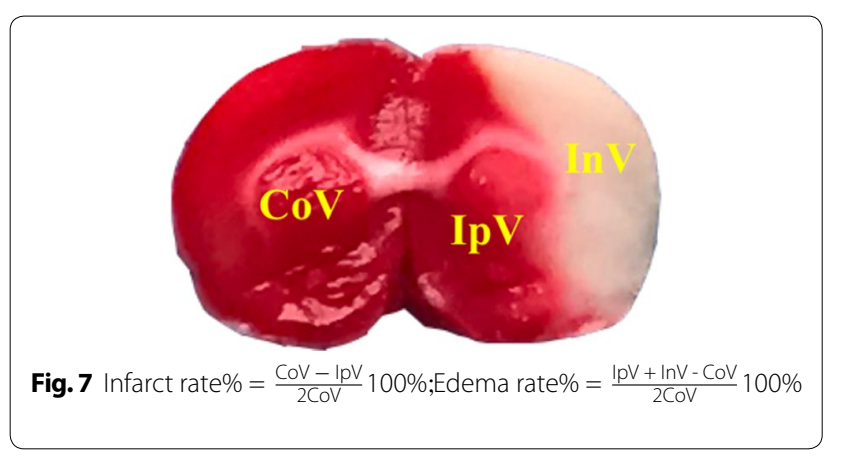

scrape the skull with a scalpel. The laser spot is located $2 \mathrm{~mm}$ behind the anterior fontanelle and $6 \mathrm{~mm}$ beside the middle line. Keep the skull moist with $37^{\circ} \mathrm{C}$ physiological saline throughout monitoring. Region of interest (ROI) 1 delineated the healthy side, ROI 2 infarcted side and ROI 3 the whole brain, corresponding to blue line, red line and green line respectively in the blood flow curve. Time of interest (TOI) delineated the relatively stable recording range to calculate the corresponding CBP, TOI 1 delineated the blood flow curve before surgery, TOI 2 during surgery and TOI 3 after surgery. CBP of two hemispheres and the whole brain was recorded before, during and after surgery at least 3 min each time.

Reduced rate of CBP $\%=\frac{\text { T1IS }- \text { T2IS }}{\text { T1IS }} 100 \%$.

T1IS: TOI 1 of infarcted side; T2IS: TOI 2 of infarcted side.

\section{Systemic inflammatory challenge with Lipopolysaccharide (LPS)}

Lipopolysaccharide (LPS, serotype: 055: B5, Sigma L2880) was administered intraperitoneally at doses of $40 \mu \mathrm{g} / 300 \mathrm{~g}$ rat $(134 \mu \mathrm{g} / \mathrm{kg})$ or $80 \mu \mathrm{g} / 300 \mathrm{~g}$ rat $(268 \mu \mathrm{g} /$ $\mathrm{kg}$ ) immediately after MCAO surgery [14-16]. No rats died or needed to be terminated due to LPS injection.

\section{Measurement of IL- 6 , TNF- $\alpha$, IL-1 $\beta$ in plasma and brain homogenates by ELISA}

$5 \mathrm{ml}$ blood was taken from inferior vena cava after rats subjected to $I / R 90 \mathrm{~min} / 3 \mathrm{~h}$, then centrifuged at $3500 \mathrm{rpm}, 4^{\circ} \mathrm{C}$ for $10 \mathrm{~min}$, and the plasma was stored in $-80^{\circ} \mathrm{C}$ refrigerator for later use. The rat was decapitated and the infarcted hemisphere was rapidly freezed with liquid nitrogen and stored in $-80{ }^{\circ} \mathrm{C}$ refrigerator for later use. After balance to room temperature, the infarcted hemisphere was grinded with high throughput tissue lapping instrument (CK1000D, Thmorganh). $500 \mu \mathrm{l}$ PMSF: RIPA (1:100) lysis buffer and $1 \mu$ l protease inhibitor was added to $100 \mathrm{mg}$ rats brain homogenates. The mixture was re-grinded to thoroughly blended, and then centrifuged at $14000 \mathrm{rpm}, 4{ }^{\circ} \mathrm{C}$ for $10 \mathrm{~min}$, and the supernatant was used for determination of protein concentration by BCA Protein Assays kit (Thermo Fisher Scientific, USA) according to the manufactures protocol by a fixed investigator who was blind to the groups. Interleukin 6 (IL-6), tumor necrosis factor $\alpha$ (TNF- $\alpha$ ), interleukin $1 \beta$ $(\mathrm{IL}-1 \beta)$ in plasma and brain homogenates was measured by ELISA kit (Invitrogen, Carlsbad, CA, USA) according to the manufactures protocol. 


\section{$\mathrm{RT}^{2}$ Profiler $^{\mathrm{TM}} \mathrm{PCR}$ array}

Sixteen rats were divided into four groups with four in each one, that was Sham group, Sham $+80 \mu \mathrm{g}$ LPS group, $\mathrm{MCAO}$ group, and $\mathrm{MCAO}+80 \mu \mathrm{g}$ LPS group. The rat subjected to I/R $90 \mathrm{~min} / 3 \mathrm{~h}$ was decapitated, then the infarcted hemisphere was rapidly washed with RNasefree water and loaded into RNase-free EP tubes, and freezed with liquid nitrogen. Investigator was required to operate the whole process quickly to avoid RNA enzyme contamination. We employed the Toll-Like Receptor Signaling Pathway PCR Array (QIAGEN, German, PARN-018Z) to detect 84 genes known to be involved in the pathway. RNA isolation, DNase treatment, and RNA clean-up were performed according to the manufacturer's protocol (Qiagen, Hilden, Germany). The isolated RNA was reverse transcribed into cDNA using the RT2 First Strand Kit (Invitrogen, Carlsbad, CA, USA). PCR was performed using the RT2 SYBR Green qPCR Master Mix (Invitrogen, Carlsbad, CA, USA) on an ABI PRISM7700 instrument (Applied Biosystems, Foster City, CA). Data normalization $\left(\Delta C_{t}\right)$ was based on correcting all $C_{t}$ values for the average $C_{t}^{\prime}$ values of several stable expressed housekeeping genes present on the array containing the gene-specific primer sets. $\left[\Delta \mathrm{C}_{\mathrm{t} 1}\right.$ (group $1)=$ average $C_{t}$-average of HK genes' $C_{t}^{\prime}$ for group 1 array; $\Delta C_{t 2}$ (group 2) = average $C_{t}-$ average of HK genes' $\mathrm{C}_{\mathrm{t}}$, for group 2 array]. The fold change between two groups was expressed as $2^{-(\Delta \mathrm{Ct} 1-\Delta \mathrm{Ct} 2)}$, that is $2^{-\Delta \Delta \mathrm{Ct}}$ [46]. All the procedures were conducted by a fixed investigator who was blind to the groups. Every group had four biological repeats.

\section{Quantitative real-time polymerase chain reaction (qRT-PCR) analysis}

The mRNA level of CXCL10 (IP-10) in the brain tissue was quantitated by real-time PCR. Total RNA was extracted manually from brain tissue using TRIZOL (Invitrogen, Carlsbad, CA, USA), then RNA was reversetranscribed to cDNA using SuperScript. III Reverse Transcriptase (Invitrogen, Carlsbad, CA, USA). The primers for CXCL10 designed by software Primer 5.0 were as follows: 5' AGCCAACCTTCCAGAAGCACCA $3^{\prime}$ (sense) and $5^{\prime}$ TCATGGAAGTCGATGCAGGTGC3' (antisense); for GAPDH used as internal control were as follows: 5' GCTCTCTGCTCCTCCCTGTTCTA3' (sense) and $5^{\prime}$ TGGTAACCAGGCGTCCGATA3 $3^{\prime}$ (antisense). The cycling programs were as follows: $95{ }^{\circ} \mathrm{C}$ for $10 \mathrm{~min}$ for $1 \mathrm{cycle}$, then $95^{\circ} \mathrm{C}$ for $10 \mathrm{~s}, 60^{\circ} \mathrm{C}$ for $60 \mathrm{~s}$, and $95{ }^{\circ} \mathrm{C}$ for $15 \mathrm{~s}$ for 40 cycles. The quantitative real-time PCR was performed using ViiA 7 Real-time PCR System (Applied Biosystems, Carlsbad, CA, USA) with $2 \times$ PCR master mix (Arraystar, USA) according to the manufacturer's protocol. The gene CXCL10 concentration of each sample is corrected by its housekeeping gene GAPDH. Relative quantification was processed by the standard curve method. All the procedures were conducted by a fixed investigator who was blind to the groups.

\section{Measurement of CXCL10 production in brain homogenates and plasma by ELISA}

The production of CXCL10 in brain homogenates and plasma was measured by ELISA kit (Cusabio biotech co., Ltd, WuHan, China) according to the manufactures protocol by a fixed investigator who was blind to the groups.

\section{GO enrichment analysis}

To explore the gene function of the different genes, we employ the GO analysis for functional annotation. The 27 different genes were imported into DAVID Bioinformatics Resources 6.7 (https://david-d.ncifcrf.gov/), which supply a high-throughput and integrated data-mining environment. The results were downloaded from the internet.

\section{PPI network construction}

To explore the protein-protein interaction (PPI) correlation, the different expression genes were mapped to the Search Tool for the Retrieval of Interacting Genes (STRING, https://string-db.org/) database. In the process of analysis, species were limited to "Rattus norvegicus" and the minimum interaction threshold was set to "medium confidence" 0.4 . The other parameters were set by default, and the target with weak correlation was removed. Based on the above results of PPI analysis, Cytoscape v3.6.1 software was employed to describe the interaction relationship. The Network Analyzer was used to analyze the topological properties, and the targets with degree $\geq$ twofold Median were selected to construct the PPI network graph.

\section{Data analysis}

Data were analyzed using Student's $t$ test for single comparisons and one-way ANOVA followed by Student's $t$ test with Bonferroni's correction or Dunnett's test for multiple comparisons. The criterion for statistical significance was $\mathrm{p}<0.05$. Data were expressed as mean \pm standard error of the mean (SEM).

\section{Abbreviations}

BP: biological process (BP); CC: cellular compartment; CNS: central nervous system; CBP: cerebral blood perfusion; Ccl2: chemokine (C-C motif) ligand 2; Csf3: colony stimulating factor 3; CXCL10: chemokine (C-X-C motif) ligand 10; CXCR3: C-X-C chemokine receptor 3; GO: Gene Ontology; IP-10: interferon gamma-induced protein 10; IL-1 $\beta$ : interleukin 1 $\beta$; IL-6: interleukin 6; LPS: lipopolysaccharide; MCAO: middle cerebral artery occlusion; MF: molecular function; PeriCam PSI: Pericam Perfusion Speckle Image; PPI: protein-protein 
interaction; ROI: region of interest; TTC: triphenyl tetrazolium chloride; TNF-a: tumor necrosis factor a.

\section{Acknowledgements}

Not applicable.

\section{Authors' contributions}

WP, XH and YH performed the experimental design, WP performed the MCAO surgery and drafted the manuscript and participated in the general management. WP and ZJ performed most of the experiments and data analysis. GF performed the GO enrichment analysis and PPI network construction. WS helped to perform the data analysis of $\mathrm{RT}^{2}$ Profiler ${ }^{\mathrm{TM}} \mathrm{PCR}$ array. ZY and LD helped to perform the biological sample collection. All authors reviewed the final manuscript. All authors read and approved the final manuscript.

\section{Funding}

This work was supported by grants from the National Natural Science Foundation of China [Grant No. 81774201 and 81830111], National Key Research and Development Program of China [2017YFC1702104, 2017YFC1702303], the 973 Program of China [No. 2015CB554406], the Youth Innovation Team of Shaanxi Universities and Shaanxi Provincial Science and Technology Department Project [No. 2016SF-378], the Fundamental Research Funds for the Central public welfare research institutes [ZXKT17058].

The funding agencies had no role in the study design, the collection, analysis, or interpretation of data, the writing of the report, or the decision to submit the article for publication.

\section{Availability of data materials}

The datasets used and/or analysed during the current study are available from the corresponding author on reasonable request.

\section{Ethics approval and consent to participate}

All procedures were approved by the Medicine Ethics Review Committee for animal experiments of the China Academy of Chinese Medical Sciences.

\section{Consent for publication}

Not applicable.

\section{Competing interests}

The authors declare that they have no competing interests.

\begin{abstract}
Author details
${ }^{1}$ Institute of Chinese Materia Medica, China Academy of Chinese Medical Sciences, Beijing 100700, China. ${ }^{2}$ Shaanxi Institute of International Trade \& Commerce, Xianyang 712046, China. ${ }^{3}$ Heilongjiang University of Chinese Medicine, Harbin 150040, China.
\end{abstract}

Received: 26 September 2019 Accepted: 19 December 2019 Published online: 27 December 2019

\section{References}

1. Pandian JD, Gall SL, Kate MP, et al. Prevention of stroke: a global perspective. Lancet. 2018;392(10154):1269-78.

2. Guan T, Ma J, Li M, et al. Rapid transitions in the epidemiology of stroke and its risk factors in China from 2002 to 2013. Neurology. 2017:89(1):53-61.

3. Luster AD. Chemokines - chemotactic cytokines that mediate inflammation. N Engl J Med. 1998;338(7):436-45

4. Emsley HCA, Hopkins SJ. Cute ischaemic stroke and infection: recent and emerging concepts. Lancet Neurol. 2008;7:341-53.

5. Mccoll BW, Allan SM, Rothwell NJ. Systemic infection, inflammation and acute ischemic stroke. Neuroscience. 2009;158:1049-61.

6. Westendorp WF, Nederkoorn PJ, Vermeij J-D, Dijkgraaf MG, van de Beek D. Post-stroke infection: a systematic review and meta-analysis. BMC Neurol. 2011;11:110.

7. Langhorne P, Stott D, Robertson L, MacDonald J, Jones L, McAlpine C, Dick F, Taylor G, Murray G. Medical complications after stroke a multicenter study. Stroke. 2000;31:1223-9.
8. Vernino S, Brown RD, Sejvar JJ, Sicks JD, Petty GW, O'Fallon WM. Causespecific mortality after first cerebral infarction a population-based study. Stroke. 2003;34:1828-32.

9. Hassan A, Khealani BA, Shafqat S, Aslam M, Salahuddin N, Syed NA, Baig SM, Wasay M. Stroke-associated pneumonia: microbiological data and outcome. Singap Med J. 2006;47(3):204-7.

10. Davenport RJ, Dennis MS, Wellwood I, Warlow CP. Complications after acute stroke. Stroke. 1996;27:415-20.

11. Katzan IL, Cebul RD, Husak SH, Dawson NV, Baker DW. The effect of pneumonia on mortality among patients hospitalized for acute stroke. Neurology. 2003;60(4):620-5.

12. Koizumi J, Yoshida Y, Nakazawa T, Ooneda G. Experimental studies of ischemic brain edema experimental model of cerebral embolism in rats in which recirculation can be introduced in the ischemic area. Jpn J Stroke. 1986;8:1-8.

13. Longa EZ, Weinstein PR, Carlson S, Cummins R. Reversible middle cerebral artery occlusion without craniectomy in rats. Stroke. 1989;20:84-91.

14. McColl BW, Rothwell NJ, et al. Systemic inflammatory stimulus potentiates the acute phase and CXC chemokine responses to experimental stroke and exacerbates brain damage via interleukin-1- and neutrophil-dependent mechanisms. J Neurosci. 2007;27(16):4403-12.

15. Dénes Á, Ferenczi S, Kovács KJ. Systemic inflammatory challenges compromise survival after experimental stroke via augmenting brain inflammation, blood- brain barrier damage and brain oedema independently of infarct size. J Neuroinflamm. 2011;8:164.

16. Yousuf S, Atif F, Sayeed I, et al. Post-stroke infections exacerbate ischemic brain injury in middle-aged rats: immunomodulation and neuroprotection by progesterone. Neuroscience. 2013;239:92-102.

17. Yousuf S, Atif F, Sayeed I, Wang J, Stein DG. Post-stroke infections exacerbate ischemic brain injury in middle-aged rats: immunomodulation and neuroprotection by progesterone. Neuroscience. 2013;239:92-102.

18. Kudo K, Hagiwara S, Hasegawa A, Kusaka J, Koga H, Noguchi T. Cepharanthine exerts anti-inflammatory effects via NF-kB inhibition in a LPS-induced rat model of systemic inflammation. J Surg Res. 2011;171(1):199-204.

19. Collins-Praino LE, Arulsamy A, Katharesan V, Corrigan F. The effect of an acute systemic inflammatory insult on the chronic effects of a single mild traumatic brain injury. Behav Brain Res. 2018;15(336):22-31.

20. da Cunha FR, Nardin P, Machado CV, et al. Enteric glial reactivity to systemic LPS administration: changes in GFAP and S100B protein. Neurosci Res. 2017;119:15-23.

21. Gasparotto J, Ribeiro CT, Bortolin RC, et al. Anti-RAGE antibody selectively blocks acute systemic inflammatory responses to LPS in serum, liver, CSF and striatum. Brain Behav Immun. 2017;62:124-36.

22. Goraca A, Huk-Kolega H, Kowalczyk A, Skibska B. Anti-oxidative and anti-inflammatory effects of lipoic acid in rat liver. Postepy Hig Med Dosw. 2015;4(69):270-6.

23. Quan Z, Quan Y, Wei Bo, et al. Protein-protein interaction network and mechanism analysis in ischemic stroke. Mol Med Rep. 2015;11:29-36.

24. Rappert A, Bechmann I, Pivneva T, et al. CXCR3-dependent microglial recruitment is essential for dendrite loss after brain lesion. J Neurosci. 2004;24(39):8500-9.

25. Canouï-Poitrine F, Luc G, Mallat Z, et al. Systemic chemokine levels, coronary heart disease, and ischemic stroke events: the PRIME study. Neurology. 2011;77:1165-73.

26. Amin M, Vakilian A, Mahmoodi MH, et al. Circulatory levels of C-X-C motif chemokine ligands 1,9, and 10 are elevated in patients with ischemic stroke. Eurasian J Med. 2017;49(2):92-6.

27. Rollins BJ. Chemokines. Blood. 1997;90:909-28.

28. Seifert HA, Collier LA, Chapman CB, et al. Pro-inflammatory interferon gamma signaling is directly associated with stroke induced neurodegeneration. J Neuroimmune Pharmacol. 2014;9:679-89.

29. Nguyen T-V, Frye JB, Zbesko JC, et al. Multiplex immunoassay characterization and species comparison of inflammation in acute and non-acute ischemic infarcts in human and mouse brain tissue. Acta Neuropathol Commun. 2016;4:100.

30. Zhang Y, Gao Z, Wang D, et al. Accumulation of natural killer cells in ischemic brain tissues and the chemotactic effect of IP-10. J Neuroinflamm. 2014;11:79. 
31. Wang X, Ellison JA, Siren A-L, et al. Prolonged expression of interferoninducible protein-10 in ischemic cortex after permanent occlusion of the middle cerebral artery in rat. J Neurochem. 1998;71:1194-204.

32. Wang XK, Ellison JA, Siren AL, Lysko PG, Yue TL, Barone FC, Shatzman A, Feuerstein GZ. Prolonged expression of interferon-inducible protein-10 in ischemic cortex after permanent occlusion of the middle cerebral artery in rat. J Neurochem. 1998;71:1194-204.

33. Wang X, Li X, Schmidt DB, Foley JJ, Barone FC, Ames RS, Sarau HM. Identification and molecular characterization of rat CXCR3: receptor expression and interferon-inducible protein-10 binding are increased in focal stroke. Mol Pharmacol. 2000;57(6):1190-8.

34. Chen C, Chu SF, Liu DD, et al. Chemokines play complex roles in cerebral ischemia. Neurochem Int. 2018;112:146-58.

35. Simpkins JW, Rajakuma G, Zhang YQ, et al. Esortgens may reduce mortality and ischemic damage caused by middle cerebral artery occlusion in the female rat. J Neurosurg. 1997;87(5):724-30.

36. Dubal DB, Rau SW, Shughrue PJ, et al. Differential modulation of estrogen receptors (ERs) in ischemic brain injury: a role for ERalpha in estradiol-mediated protection against delayed cell death. Endocrinology. 2006:147(6):3076-84.

37. Toung TJ, Tragsmtna RJ, Hurn PD. Esrtogen-mediated neuroprotection after experimented stroke in male rats. Stroke. 1998;29(8):1666-700.

38. Yuan $Y$, Zha H, Rangarajan P, et al. Anti-inflammatory effects of Edaravone and Scutellarin in activated microglia in experimentally induced ischemia injury in rats and in BV-2 microglia. BMC Neurosci. 2014;15:125.

39. Fang $M$, Yuan $Y$, Rangarajan $P$, et al. Scutellarin regulates microglia-mediated TNC1 astrocytic reaction and astrogliosis in cerebral ischemia in the adult rats. BMC Neurosci. 2015;25(16):84.
40. Yuan Y, Rangarajan P, Kan EM, et al. Scutellarin regulates the Notch pathway and affects the migration and morphological transformation of activated microglia in experimentally induced cerebral ischemia in rats and in activated BV-2 microglia. J Neuroinflamm. 2015;20:12.

41. Fang $Q$, Yan X, Li S, et al. Methylene blue ameliorates ischemia/ reperfusion-induced cerebral edema: an MRI and transmission electron microscope study. Acta Neurochir Suppl. 2016;121:227-36.

42. Liu Y, Meng R, Yan F, et al. Evaluation of rat MCAO model by laser Doppler flowmetry. Chin J Pathophysiol. 2011;27(3):620-4.

43. Wang R, Liu X, Zhang Y et al. Correlation between neurological deficits scores and infarct volume in focal cerebral ischemia in rats. J Cap Med Univ. 2013;34(1): 69-74.

44. Wang G, Zhang YP, Gao Z, et al. Pathophysiological and behavioral deficits in developing mice following rotational acceleration-deceleration traumatic brain injury. Dis Model Mech. 2018;11(1):dmm030387.

45. Haiping Z, Ma S, Yan F, et al. Application of blood flow perfusion imager PeriCam PSI in experimental teaching of cerebral ischemia in mice. Life Sci Instrum. 2018;16:48-58.

46. Livak KJ, Schmittgen TD. Analysis of relative gene expression data using real-time quantitative PCR and the 2(-Delta Delta $C(T))$ method. Methods. 2001;25:402-8.

\section{Publisher's Note}

Springer Nature remains neutral with regard to jurisdictional claims in published maps and institutional affiliations.
Ready to submit your research? Choose BMC and benefit from:

- fast, convenient online submission

- thorough peer review by experienced researchers in your field

- rapid publication on acceptance

- support for research data, including large and complex data types

- gold Open Access which fosters wider collaboration and increased citations

- maximum visibility for your research: over 100M website views per year

At BMC, research is always in progress.

Learn more biomedcentral.com/submissions 